\title{
Surface acid-base characteristics of natural manganese mineral particles
}

\author{
Ruixia Liu*, Hongxiao Tang \\ State Key Laboratory of Environmental Aquatic Chemistry, Research Center for Eco-Environmental Sciences, \\ Chinese Academy of Sciences, PO Box 2871, Beijing 100085, People's Republic of China
}

Received 25 October 2000; accepted 20 June 2001

\begin{abstract}

$$
\begin{aligned}
& \text { Model I: } \quad \equiv \mathrm{MnOH}_{2}^{+} \leftrightarrow \equiv \mathrm{MnOH}+\mathrm{H}^{+}, \quad \mathrm{K}_{\mathrm{a} 1}^{\mathrm{int}}=3.52-3.60 \\
& \equiv \mathrm{MnOH} \leftrightarrow \mathrm{MnO}^{-}+\mathrm{H}^{+}, \quad \mathrm{K}_{\mathrm{a} 2}^{\mathrm{int}}=4.04-4.88 \\
& \text { Model II: } \quad \equiv \mathrm{MnOH} \leftrightarrow \equiv \mathrm{MnO}^{-}+\mathrm{H}^{+}, \quad \mathrm{K}_{\mathrm{a}}^{\mathrm{int}}=5.06-5.62
\end{aligned}
$$

In this paper, the acid-base characteristics of natural manganese mineral collected from Guangxi Province, China, are investigated by potentiometric titration and solubility experiments. The constant capacitance surface complexation model is used to interpret experimental data. The calculations are performed with the least-squares FITEQL program 2.0. All the model parameters are determined on the base of the experimental data. This study indicates that the proton reactions in the acidic blank can be successfully described by those of $\mathrm{Mn}^{2+}$ in solution. To explain the surface acid-base behavior of manganese mineral particle, two protonation models are proposed

Optimization results indicate that these two models can simulate the experimental results very well. The applicability of the constant capacitance model (CCM) in describing the surface reaction of natural manganese mineral is further verified. (C) 2002 Elsevier Science B.V. All rights reserved.

Keywords: Natural manganese mineral; Acid-base characteristic; Potentiometric titration; Constant capacitance model

\section{Introduction}

Natural aquatic particles are one of the most important factors controlling the concentrations and speciations of pollutants in aquatic environments. For example the interfacial reactions of pollutants on natural particle play a dominant

\footnotetext{
* Corresponding author. Fax: + 86-10-62923543.
}

E-mail address: rachel@mail.rcees.ac.cn (R. Liu). role in their behavior, transport and ultimate fate in natural waters.

Natural transition metal oxide/hydroxide minerals as suspended particles, widely distributed in surface waters, are potential oxidizing agents for natural or synthetic organics [1-3]; manganese minerals are one primary group. Although the manganese oxide component in soils and aquatic sediments is generally low, accumulation of manganese oxide can occur when $\mathrm{Mn}^{2+}$ (aq) generated 
by reduction reaction under anoxic condition diffuses into oxic environments and becomes reoxidized and precipitated in the vicinity of oxic/anoxic interface [4]. In China though natural manganese minerals containing $\mathrm{Mn}$ (III) and $\mathrm{Mn}(\mathrm{IV})$ are indeed abundant and the oxidation of organic compounds by manganese minerals is an important degradative pathway in some environments. Therefore, the role of manganese oxide in the surface chemistry of natural particles, participating in a number of oxidation reactions involving both organics and inorganics, cannot be neglected.

Over the past decades, redox reactions at the manganese oxide/solution interface have received considerable attention. It has been pointed that a manganese oxide suspension can be reduced and dissolved by natural organics [5,6] and by simple organic compounds such as phenols and organic acids $[3,7,8]$. To date the focus of interest has been the oxidation of organic compounds at the manganese oxides surface [4,9-11]. In recent research, the oxidative decolorization of dye compounds by natural manganese mineral has been found in our laboratory (see Fig. 1) [12] and attributed to the interfacial behavior of dye compounds on manganese mineral particles. In order to characterize the surface reaction properties of the dye com-

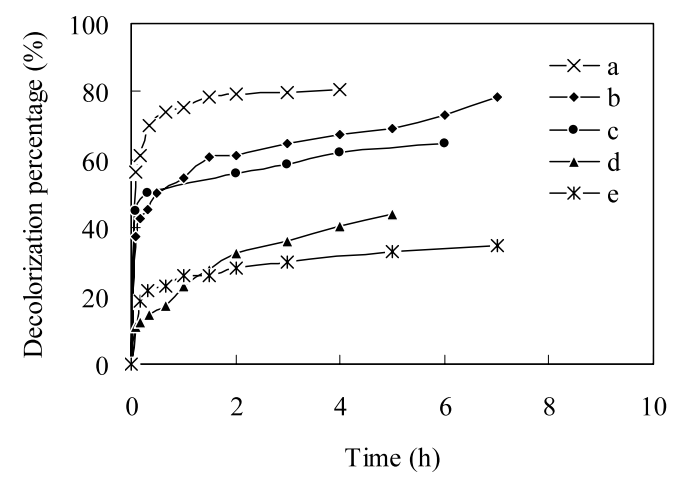

Fig. 1. Decolorization percentages of different dye compounds as a function of time [12] (reaction condition: particle concentration, $2 \mathrm{~g}^{-1}$ (200 mesh); temperature, $25^{\circ} \mathrm{C}$; dye concentration, $20 \mathrm{mg} \mathrm{l}^{-1}$; (a) Mordant black 2B, pH 5.0; (b) reactive brilliant red K-2G, pH 3.50; (c) direct light red F3B, pH 4.0; (d) acid complex blue RRN, pH 6.0; (e) cationic pink 2FG, $\mathrm{pH}$ 4.5). pounds on the manganese mineral particle, it is necessary to investigate the surface acid-base properties of the natural manganese mineral. Up to now many studies have interpreted the surface reactive characteristics of natural particles using surface complexation models [13-15], in which various models, such as constant capacitance model (CCM), diffuse-lager model (DLM), triplelayer and four-layer models (FLM) have been developed. Due to its simplicity and practicality, the CCM has been modified intensively and applied to describe the amphoteric surface behavior of oxides [16,17] and sulfide minerals [18,19], and to investigate the interfacial reaction properties of kaolinite [20-22], montmorillonite [23] and illite $[24,25]$. But the surface acid-base properties of natural manganese mineral particles have not been widely investigated by surface complexation model.

The objectives of this current research are to examine the applicability of CCM in describing the interfacial behavior of natural manganese mineral particles, to describe a modeling methodology for determining the surface parameters and to interpret the surface reaction characteristics of manganese mineral particles.

\section{Materials and methods}

\subsection{Materials}

The natural manganese mineral samples were collected from Guangxi Province, China, then were ground and passed through 200-mesh stainless steel sieves. The total manganese and oxidation state of manganese of the mineral particles were measured, respectively, by atomic absorption spectrophotometer (AAS, Model Z-6100, HITACHI) and back-titration of excess oxalate with permanganate [26]. The content of $\mathrm{Mn}$ (II) could be obtained from the difference of total manganese and oxidation state manganese. Other elemental compositions were determined using X-ray fluorescence spectrograph (Model 3070). In combination with X-ray diffraction analysis, as shown in Fig. 2, the stronger peaks at d-spacing of 3.345, 4.283 and $2.457 \AA$ as well as the three peaks at 


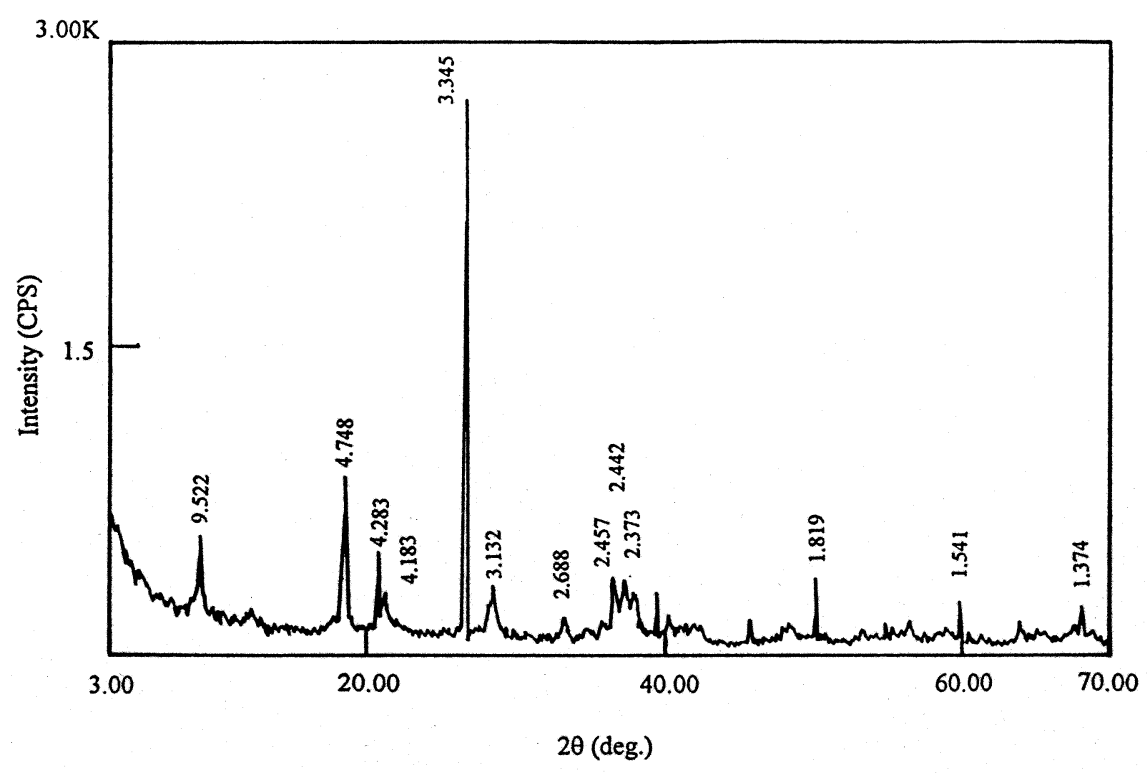

Fig. 2. X-ray diffraction spectrum of natural manganese mineral.

$2.442,4.183$ and $2.688 \AA$ were attributed to silicon oxide and ferrihydrite, respectively. The major peaks of manganese oxide were found at 4.748 , 9.522 and $2.373 \AA$, which were consistent with those reported for $\alpha-\mathrm{Mn}_{2} \mathrm{O}_{3}$ [12]. Therefore, these results showed that silicon, manganese and ferric are major components of the mineral. The BET surface area and organic substrates content in the mineral were obtained using $\mathrm{N}_{2} / \mathrm{BET}$ method (ASAP Model 2000) and potassium dichromate method, respectively. All results are presented in Table 1. In addition, a stock suspension of $20 \mathrm{~g}$ $1^{-1}$ was prepared and stored in a refrigerator for 2 weeks prior to the solubility and potentiometric titration experiments.

\subsection{Solubility of manganese mineral suspensions at various $\mathrm{pHs}$}

The solubility test of manganese mineral suspensions was performed in batch systems. A 40$\mathrm{ml}$ sample suspension containing 1 or $5 \mathrm{~g}^{-1}$ manganese mineral particle was adjusted to the $\mathrm{pH}$ between 2 and 10 with diluted $\mathrm{NaOH}$ and $\mathrm{HNO}_{3}$. All the slurries were shaken at a $25 \pm$ $1{ }^{\circ} \mathrm{C}$ constant temperature air-bath (Model HZQ-
C) for $24 \mathrm{~h}$. The final $\mathrm{pH}$ of each suspension was measured, and suspension aliquots filtered through a $0.45-\mu \mathrm{m}$ syringe-end filter. Then, the concentrations of $\mathrm{Mn}, \mathrm{Fe}, \mathrm{Al}, \mathrm{Si}, \mathrm{Ca}, \mathrm{Na}, \mathrm{K}, \mathrm{Mg}$, $\mathrm{S}$ and $\mathrm{P}$ in filtrate were determined by inductively coupled plasma-atomic emission spectrometer (ICP-AES, Model Jarrell-Ash 1155V). No background electrolyte was used in this procedure.

Table 1

Chemical composition and BET surface area of natural manganese mineral

\begin{tabular}{lc}
\hline Components & Content \\
\hline $\mathrm{MnO}_{2}(\%)$ & 42.6 \\
$\mathrm{MnO}(\%)$ & 4.6 \\
$\mathrm{Fe}(\%)$ & 7.26 \\
$\mathrm{Si}(\%)$ & 8.66 \\
$\mathrm{Al}(\%)$ & 3.05 \\
$\mathrm{Ca}(\%)$ & 0.39 \\
$\mathrm{Mg}(\%)$ & 0.28 \\
$\mathrm{~K}(\%)$ & 0.42 \\
$\mathrm{Na}(\%)$ & 0.23 \\
$\mathrm{P}(\%)$ & 0.14 \\
$\mathrm{~S}(\%)$ & 0.11 \\
Organic substrates $(\%)$ & 0.17 \\
$\mathrm{BET}$ surface area $\left(\mathrm{m}^{2} \mathrm{~g}^{-1}\right)$ & 29.8
\end{tabular}




\subsection{Potentiometric titration of manganese mineral suspensions}

The dissolution of $\mathrm{Mn}(\mathrm{II})$ from the manganese mineral can consume protons during the addition of acid, causing errors in the evaluation of the surface acid-base properties of the manganese mineral particles from the results of potentiometric titration. This problem may be solved by using a backtitration procedure. A certain volume of 20 $\mathrm{g} 1^{-1}$ stock suspension was added to $100-\mathrm{ml}$ flask, and the ionic strength in the suspensions adjusted with $1 \mathrm{~mol}^{-1} \mathrm{NaNO}_{3}$. The initial volume of the suspension was diluted to $80 \mathrm{ml}$. The suspension was stirred magnetically and continually bubbled with $\mathrm{N}_{2}$ purified successively through $10 \% \mathrm{NaOH}$, $10 \% \mathrm{H}_{2} \mathrm{SO}_{4}$, distilled water, and $0.1 \mathrm{~mol} 1^{-1}$ $\mathrm{NaNO}_{3}$ to purge $\mathrm{CO}_{2}$ until the electrode potential was stable. Afterward, $1.5 \mathrm{ml}$ of $0.09487 \mathrm{~mol} \mathrm{1}^{-1}$ $\mathrm{HNO}_{3}$ was added and the equilibrium $\mathrm{pH}$ value of the suspension decreased to less than 3 , and the back titration process was carried out with the addition of $0.02463 \mathrm{~mol}^{-1} \mathrm{NaOH}$ in increments of $0.1 \mathrm{ml}$ until the $\mathrm{pH}$ of the suspension reached 10.50. During the titration procedure, the drift of the measured potential should be below $1 \mathrm{mV}$ $\mathrm{h}^{-1}$ and the temperature kept at $20 \pm 0.5{ }^{\circ} \mathrm{C}$. The reference blank was prepared in the same manner as the sample. The acidic suspension with $\mathrm{HNO}_{3}$ was centrifuged at $10000 \mathrm{rpm}$ for $30 \mathrm{~min}$. The acidic supernatants as system blanks were obtained and titrated.

\section{Results and discussion}

\subsection{Solubility of manganese mineral suspension}

In the solubility test, the release of $\mathrm{Fe}, \mathrm{Mg}$ and $\mathrm{P}$ is not found in the range of $\mathrm{pH}$ from 2 to 10 . The release of the other elements are shown in Fig. 3. As can be seen, the amount of $\mathrm{Al}, \mathrm{Si}, \mathrm{Ca}$ and $\mathrm{Na}$ in solution is low and appears to be insensitive to the change of $\mathrm{pH}$. The concentration of $\mathrm{K}$ released to solution is high relative to those of other elements and is independent of the particle concentration and $\mathrm{pH}$. The release of $\mathrm{K}^{+}$ may be attributed to cation exchange reaction
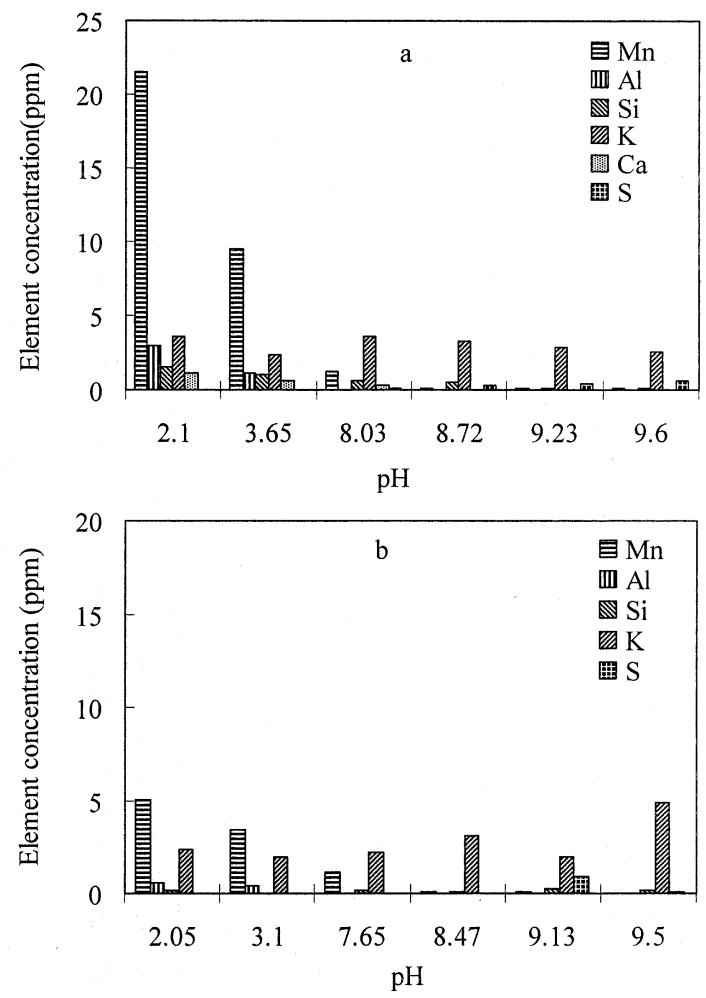

Fig. 3. Solubility of natural manganese mineral suspension at various pHs, (a) $5 \mathrm{~g} \mathrm{l}^{-1}$ suspension concentration; (b) $1 \mathrm{~g} \mathrm{l}^{-1}$ suspension concentration.

occurring at the permanent negatively charges sites: $\equiv \mathrm{SK}+\mathrm{Na}^{+}\left(\mathrm{H}^{+}\right)=\equiv \mathrm{SNa}(\mathrm{H})+\mathrm{K}^{+}$. Striking differences are seen for $\mathrm{Mn}$ dissolution (Fig. 3). The amount of dissolved $\mathrm{Mn}$ increases with a decrease of $\mathrm{pH}$ value and an increase of particle concentration. No notable $\mathrm{Mn}$ dissolution is observed at $\mathrm{pH}$ greater than 8 . This phenomenon can be explained from two points; one is that $\mathrm{Mn}(\mathrm{II})$ in the crystal structure of $\alpha-\mathrm{Mn}_{2} \mathrm{O}_{3}$, as a result of high mobility, releases from solid surface to solution in acidic aqueous solution; the other is that $\mathrm{Mn}(\mathrm{IV})$ in the crystal structure can be reduced thermodynamically to $\mathrm{Mn}(\mathrm{II})$ at low $\mathrm{pH}$.

\subsection{Determination of zero titration point and total surface site concentration}

In previous studies, the in situ Gran plot has been used to determine the standard electrode 

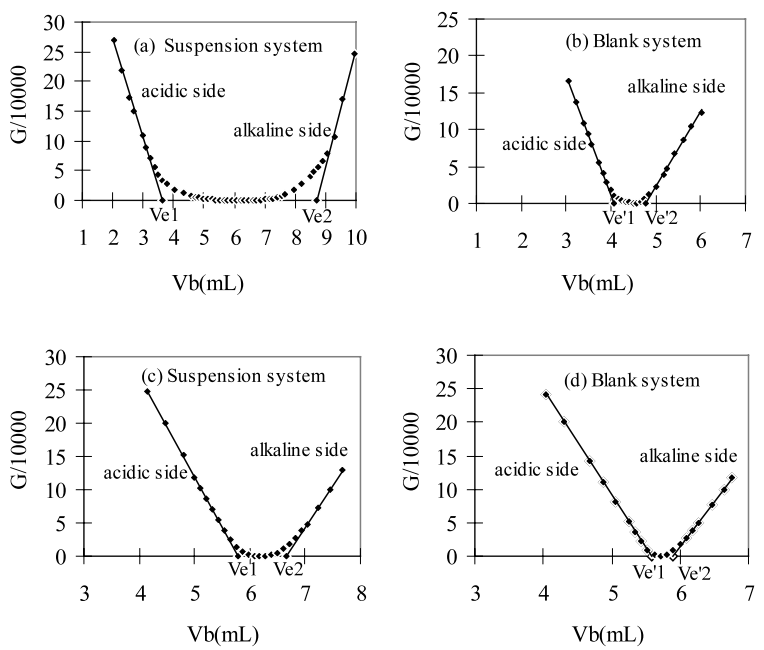

Fig. 4. Gran plots for different titration systems, (a) and (b) 5 $\mathrm{g}^{-1}$ suspension concentration in $0.1 \mathrm{~mol}^{-1} \mathrm{NaNO}_{3}$; (c) and (d) $1 \mathrm{~g}^{-1}$ suspension concentration in $0.1 \mathrm{~mol} \mathrm{1}^{-1} \mathrm{NaNO}_{3}$.

potential and the volume of titrant added at the equivalence point for solid/water system [2325,27,28]. The Gran plots for the current manganese mineral particle and the related acidic blank systems are shown in Fig. 4 where the Gran function $(G)$ is plotted against the volume of added sodium hydroxide solution $\left(V_{\mathrm{B}}\right)$. For the hydroxide back titration, Gran functions are expressed as

acidic side: $\quad G=\left(V_{0}+V_{\mathrm{AT}}+V_{\mathrm{B}}\right) \times 10^{E / 59.175}$

alkaline side:

$G=\left(V_{0}+V_{\mathrm{AT}}+V_{\mathrm{B}}\right) \times 10^{-E / 59.175}$

where $V_{0}$ is the initial volume of suspension $(\mathrm{ml})$; $V_{\mathrm{AT}}$ is the total volume of nitric acid added (ml); and $E$ is the potential of the glass electrode $(\mathrm{mV})$. With linear regression analysis of the Gran plots the two equivalence points for each suspension (Ve1 and Ve2) or for the blank system (Ve'1 and $\left.\mathrm{Ve}^{\prime} 2\right)$, the intercepts at the $V$-axis in acidic and alkaline side, are obtained.

During the hydroxide back titration procedure for the suspension system, the added $\mathrm{OH}^{-}$successively participates in the following reactions, acid-base neutralization with excess $\mathrm{H}^{+}$in solution (before Ve1); interaction with various active sites on the particle interface (from Ve1 to Ve2), and raising the $\mathrm{pH}$ of the suspension (after Ve2). Therefore, Vel is considered to be the zero titration point (ZPT) of the suspension system and applied to calibrate the total concentration of reacted protons $(\mathrm{TOTH})$ in each titration point.

$\mathrm{TOTH}=-\frac{\left(V_{\mathrm{B}}-\mathrm{Ve} 1\right) \times C_{\mathrm{B}}}{\left(V_{0}+V_{\mathrm{AT}}+V_{\mathrm{B}}\right)} \quad\left(\mathrm{mol} \mathrm{1} 1^{-1}\right)$

The calibrated titration data sets, TOTH versus $\mathrm{pH}$, are arranged in the format of data input for FITEQL program (2.0) to calculate the surface acidic constants.

Based on the Gran plot, the reaction of $\mathrm{OH}^{-}$ added on the particle surface occurs between Ve1 and Ve2. Therefore, the total surface site concentration $\left(H_{\mathrm{s}}\right)$ can be estimated from the following equation.

$$
\mathrm{H}_{\mathrm{s}}=\frac{\left[(\mathrm{Ve} 2-\mathrm{Ve} 1) \times C_{\mathrm{B}}-\left(\mathrm{Ve}^{\prime} 2-\mathrm{Ve}^{\prime} 1\right) \times C_{\mathrm{B}}\right]}{V_{0}}
$$

$\left(\mathrm{mol} \mathrm{1} 1^{-1}\right)$

All the results are summarized in Table 2.

\subsection{Acid-base reaction description of blank system}

The natural manganese mineral is mainly composed of manganese oxide. In acidic solution, the

Table 2

Equivalence points and total surface site concentrations for various titration systems

\begin{tabular}{|c|c|c|c|c|c|}
\hline System & Vel (ml) (pH) & $\mathrm{Ve} 2(\mathrm{ml})(\mathrm{pH})$ & $\mathrm{Ve}^{\prime} 1(\mathrm{ml})(\mathrm{pH})$ & $\mathrm{Ve}^{\prime} 2(\mathrm{ml})(\mathrm{pH})$ & $H_{\mathrm{s}}\left(\mathrm{mol} \mathrm{l}^{-1}\right)$ \\
\hline $\begin{array}{c}C_{\mathrm{s}}=5 \mathrm{~g} \mathrm{l}^{-1} ; I=0.1 \mathrm{~mol} \mathrm{l}^{-1} \\
\mathrm{NaNO}_{3} ; \text { initial pH } 5.78\end{array}$ & $3.640(4.23)$ & $8.720(9.98)$ & $4.075(4.77)$ & $4.778(9.15)$ & $1.35 \times 10^{-3}$ \\
\hline $\begin{array}{c}C_{\mathrm{s}}=1 \mathrm{~g} \mathrm{l}^{-1} ; I=0.1 \mathrm{~mol} \mathrm{l}^{-1} \\
\mathrm{NaNO}_{3} ; \text { initial pH } 5.51\end{array}$ & $5.788(4.81)$ & $6.661(9.30)$ & $5.587(4.18)$ & $5.895(5.16)$ & $1.71 \times 10^{-4}$ \\
\hline
\end{tabular}


Table 3

Comparison of total Mn concentration obtained using two methods (for the acidic blank)

\begin{tabular}{|c|c|c|c|c|}
\hline \multirow[t]{2}{*}{ System } & \multicolumn{3}{|c|}{ Model optimization result } & \multirow{2}{*}{$\begin{array}{l}\text { Result from ICP analysis } \\
\text { TOTMn }\left(\mathrm{mol} \mathrm{l}^{-1}\right)\end{array}$} \\
\hline & TOTMn $\left(\mathrm{mol} \mathrm{l}^{-1}\right)$ & $S_{\mathrm{Mn}}^{\mathrm{a}}$ & $V_{\mathrm{Y}}^{\mathrm{a}}$ & \\
\hline
\end{tabular}

${ }^{\text {a }} S_{\mathrm{Mn}}$ is $\mathrm{SD}$ of TOTMn. $V_{\mathrm{Y}}$ is the overall variance, an indicator of the goodness of fit.

dissolution of manganese oxide is obvious relative to that of neutral condition (see Fig. 3). Thus, the proton reactions in the acidic supernatants of the suspension can be assumed as those of $\mathrm{Mn}^{2+}$ in solution. The chemical equations and corresponding reaction constants $\left(T=25^{\circ} \mathrm{C}, I=0\right)$ are presented as follows [29].

$$
\begin{gathered}
\mathrm{Mn}^{2+}+\mathrm{H}_{2} \mathrm{O}=\mathrm{MnOH}^{+}+\mathrm{H}^{+}, \\
\log \mathrm{K}=-10.1 \\
\mathrm{Mn}^{2+}+2 \mathrm{H}_{2} \mathrm{O}=\mathrm{Mn}(\mathrm{OH})_{2}+2 \mathrm{H}^{+}, \\
\log \mathrm{K}=-15.3
\end{gathered}
$$

The titration data is analyzed by FITEQL program, in which the total $\mathrm{Mn}$ concentration (TOTMn) in the blank is arranged as an adjustable parameter. From the model calculation results of the titration data and analytical results by ICP-AES presented in Table 3, it is indicated that TOTMn values obtained from the two methods show insignificant differences. Moreover, good agreement is observed between the experiment data and the model curves, as shown in Fig. 5. All the results indicate that the acid-base reactions of the blank system can be described by those of $\mathrm{Mn}^{2+}$ in solution.

\subsection{Model description of manganese mineral suspension system}

In CCM, only one plane in the interfacial region is considered and all surface complexes are arranged as inner-sphere complexes. The electrical double layers are Helmholtz, and like a capacitor with a pair of plates in parallel [30,31]. In the model calculations, an electric capacity $(C)$, the total surface site concentration $\left(H_{\mathrm{s}}\right)$ and the optimized intrinsic acidic constants are arranged as adjustable parameters. Then, by inputting different values of $C$, the best fit is achieved.

In this study, the CCM is applied to determine the surface acidic constants of the manganese mineral particle. Due to the use of high background electrolyte concentration $\left(0.1 \mathrm{~mol}^{-1}\right.$ $\mathrm{NaNO}_{3}$ ), ion exchange reactions are usually much weaker and can be neglected. Therefore, the acidbase behavior of the manganese mineral particle surface as the amphoteric surface hydroxyl groups $(\equiv \mathrm{MnOH})$ is only considered in describing the interfacial reactions of the samples. Two surface protonation models are used to determine the surface acidity constants. In model I, it is assumed that the particle surface is homogeneous, and subject to protonation and deprotonation as follows.

$$
\equiv \mathrm{MnOH}_{2}^{+} \leftrightarrow \equiv \mathrm{MnOH}+\mathrm{H}^{+}, \quad \mathrm{K}_{\mathrm{a} 1}^{\mathrm{int}}
$$

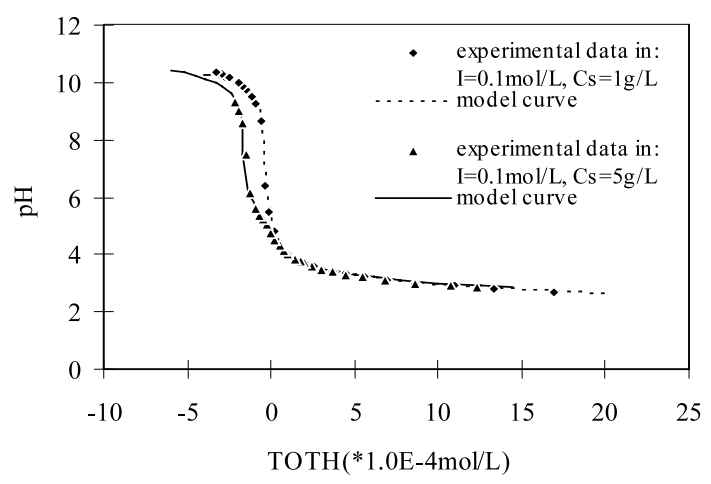

Fig. 5. Titration curves for acidic blank systems and corresponding model calculation curves. 
Table 4

Surface characteristic parameters of manganese mineral particle

\begin{tabular}{|c|c|c|c|c|c|c|c|}
\hline \multirow[t]{2}{*}{ System } & \multicolumn{4}{|c|}{ Model I } & \multicolumn{3}{|c|}{ Model II } \\
\hline & $\mathrm{K}_{\mathrm{a} 1}^{\mathrm{int}}$ & $\mathrm{K}_{\mathrm{a} 2}^{\mathrm{int}}$ & $H_{\mathrm{s}}\left(\mathrm{mol} \mathrm{1} 1^{-1}\right)$ & $V_{\mathrm{Y}}$ & $\mathrm{K}_{\mathrm{a}}^{\mathrm{int}}$ & $H_{\mathrm{s}}\left(\mathrm{mol} \mathrm{1} 1^{-1}\right)$ & $V_{\mathrm{Y}}$ \\
\hline$C_{\mathrm{s}}=1 \mathrm{~g} \mathrm{l}^{-1} ; I=0.1 \mathrm{~mol} \mathrm{l}^{-1} \mathrm{NaNO}_{3}$ & 3.60 & 4.88 & $2.04 \times 10^{-4}$ & 16.3 & 5.62 & $1.93 \times 10^{-4}$ & 10.2 \\
\hline$C_{\mathrm{s}}=5 \mathrm{~g} \mathrm{l}^{-1} ; I=0.1 \mathrm{~mol} \mathrm{l}^{-1} \mathrm{NaNO}_{3}$ & 3.52 & 4.04 & $1.20 \times 10^{-3}$ & 48.4 & 5.06 & $1.10 \times 10^{-3}$ & 50.9 \\
\hline
\end{tabular}

$\equiv \mathrm{MnOH} \leftrightarrow \equiv \mathrm{MnO}^{-}+\mathrm{H}^{+}, \quad \mathrm{K}_{\mathrm{a} 2}^{\mathrm{int}}$

In model II, only the release of protons from the particle surface is considered to form negatively charged surface sites.

$\equiv \mathrm{MnOH} \leftrightarrow \equiv \mathrm{MnO}^{-}+\mathrm{H}^{+}, \quad \mathrm{K}_{\mathrm{a}}^{\mathrm{int}}$

By these two models, the surface acidic constants for different manganese mineral suspensions are obtained. The parameters are listed in Table 4. As shown, the $H_{\mathrm{s}}$ values obtained by model optimization are consistent with the $H_{\mathrm{s}}$ values estimated by Eq. (4) (see Table 2). For all the calculations, the overall variance $\left(V_{\mathrm{Y}}\right)$ values, which are the indicator of the fit, vary from 10.2 to 50.9. In turn, the parameters are used in the models to reproduce titration curves shown in Fig. 6. It can be seen that model calculation results match well with the experimental results. Table 4 also shows that the $V_{\mathrm{Y}}$ values for $5 \mathrm{~g}^{-1}$ suspension are a bit higher than those of $1 \mathrm{~g}^{-1}$ suspension. This can mainly be attributed to the difference between the model assumptions and the real titration system. In the calculations of the models I and II, the particle surface is considered to be homogeneous. However, clearly the surface

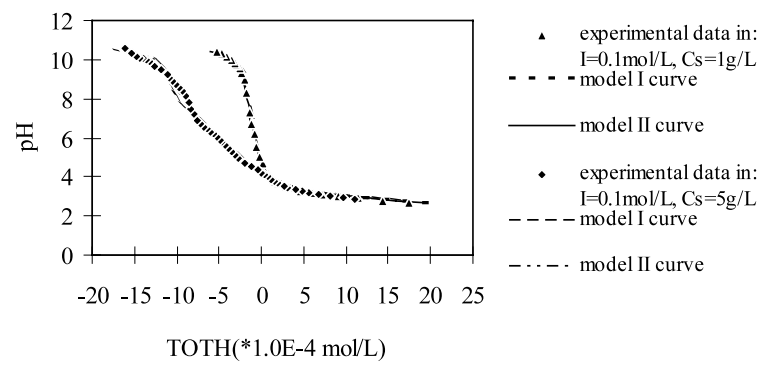

Fig. 6. Model curves of potentiometric titration for manganese mineral suspensions and corresponding experimental data. tends to be heterogeneous when the particle concentration increases.

\section{Conclusions}

On the base of potentiometric titration experiments and constant capacitance surface complexation model calculations, it is shown that the proton reactions in acidic supernatants of the system blanks are the result of $\mathrm{Mn}^{2+}$ release in acidic medium. The proposed models can reasonably simulate the titration experimental data of different particle concentrations. It is also shown that the CCM may provide a means for determining the surface parameters of natural manganese mineral and interpreting the surface reaction characteristics of manganese mineral particles.

\section{Acknowledgements}

This research was supported by Natural Sciences Foundation of China (No. 20037010).

\section{References}

[1] B.M. Voelker, F.M.M. Morel, B. Sulzberger, Iron redox cycling in surface water: effect of humic substances and light, Environ. Sci. Technol. 31 (4) (1995) 1004-1011.

[2] G. Karametaxas, S.J. Hug, B. Sulzberger, Photodegradation of EDTA in the presence of lepidocrocite, Environ. Sci. Technol. 29 (12) (1995) 2992-3000.

[3] A.T. Stone, J.J. Morgan, Reduction and dissolution of manganese (III) and manganese (IV) oxides by organics: 1. Reaction with hydroquinone, Environ. Sci. Technol. 18 (1984) 450-456.

[4] H.J. Ulrich, A.T. Stone, Oxidation of chlorophennols adsorbed to manganese oxide surface, Environ. Sci. Technol. 23 (1989) 421-428. 
[5] W.G. Sunda, S.A. Huntsman, G.R. Harvey, Photoreduction of manganese oxides in seawater and its geochemical and biological implications, Nature 301 (1983) 234-236.

[6] T.D. Waite, I.C. Wrigley, R. Szymozak, Photoassisted dissolution of a colloidal manganese oxide in the presence of fulvic acid, Environ. Sci. Technol. 22 (1988) 778-785.

[7] A.T. Stone, J.J. Morgan, Reduction and dissolution of manganese (III) and manganese (IV) oxides by organics: 2. Survey of the reactivity of organics, Environ. Sci. Technol. 18 (1984) 617-624.

[8] A.T. Stone, Reductive dissolution of manganese (III/IV) oxides by substituted phenols, Environ. Sci. Technol. 21 (1987) 979-988.

[9] W.G. Sunda, D.J. Kieber, Oxidation of humic substances by manganese oxides yields low-molecular-weight organic substrates, Nature 367 (1994) 62-64.

[10] B.W. Wang, R.G. Burau, Oxidation of dimethylselenide by $\delta-\mathrm{MnO}_{2}$ : oxidation product and factors affecting oxidation rate, Environ. Sci. Technol. 29 (1995) 1504-1510.

[11] H. Zheng, H.X. Tang, Adsorption and degradation of phenol on natural manganese ore surfaces, Huanjing Kexue Xuebao 19 (6) (1999) 619-624.

[12] R.X. Liu, H.X. Tang, Oxidative decolorization of direct light red F3B dye at natural manganese mineral surface, Water Res. 34 (2000) 4029-4035.

[13] J. Chorover, G. Sposito, Dissolution behavior of kaolinite tropical soils, Geochim. Cosmochim. Acta 59 (1995) 3109-3121.

[14] F.Y. Wang, J.S. Chen, W. Forsling, Modeling sorption of trace metals on natural sediments by surface complexation model, Environ. Sci. Technol. 31 (1997) 448-453.

[15] X.H. Wen, Q. Du, H.X. Tang, Surface complexation model for the heavy metal adsorption on natural sediment, Environ. Sci. Technol. 32 (1998) 870-875.

[16] L.M. Sigg, Die Wechselwirkung von anionen und schwachen säuren mit $\alpha$-FeOOH (Goethit) in wässriger Lösung, Ph.D. Thesis, Swiss Federal Institute of Technology, Zurich, 1979.

[17] L. Lövgren, S. Sjöberg, P.W. Schindler, Acid/base reaction and $\mathrm{Al}$ (III) complexation at the surface of goethite, Geochim. Cosmochim. Acta 54 (1990) 1301-1306.

[18] Z.X. Sun, W. Forsling, L. Rönngren, S. Sjöberg, P.W. Schindler, Surface reactions in aqueous metal sulfide sys- tems. 3. Ion exchange and acid/base properties of hydrous lead sulfide, Colloids Surf. 59 (1991) 243-254.

[19] L. Rönngren, S. Sjöberg, Z.X. Sun, W. Forsling, Complexation at the metal sulfide-water interface, in: K.A. Matis (Ed.), Flotation Science and Engineering, Marcel Dekker, New York, 1995, pp. 179-205.

[20] P.W. Schindler, P. Liechti, J.C. Westall, Adsorption of copper, cadmium and lead from aqueous solution to the kaolinite/water interface, Neth. J. Agric. Sci. 35 (1987) 219-230.

[21] E. Wieland, W. Stumm, Dissolution kinetics of kaolinite in acidic aqueous solution at $25^{\circ} \mathrm{C}$, Geochim. Cosmochim. Acta 56 (1992) 3339-3355.

[22] W. Stumm, Chemistry of the solid-water interface, in: Processes at the Mineral-Water and Particle-Water Interface in Natural System, Wiley, New York, 1992 Chapter 3 and 5.

[23] M. Stadler, P.W. Schindler, Modeling of $\mathrm{H}^{+}$and $\mathrm{Cu}^{2+}$ adsorption on calcium-montmorillonte, Clays Clay Miner. 41 (1993) 556-559.

[24] Q. Du, Z.X. Sun, W. Forsling, H.X. Tang, Acid-base properties of aqueous illite surfaces, J. Colloid Interf. Sci. 197 (1997) 221-231.

[25] W.X. Liu, Z.X. Sun, W. Forsling, Q. Du, H.X. Tang, A comparative study of surface acid-base characteristics of natural illite from different origins, J. Colloid Interf. Sci. 219 (1999) 48-61.

[26] Wuhan University, Analysis Chemical Experiment, High Education Press, Beijing, 1984, pp. 308-309.

[27] J. Chorover, G. Sposito, Surface charge characteristics of kaolinitic tropical soils, Geochim. Cosmochim. Acta 59 (1995) 875-884.

[28] C. Ludwig, P.W. Schindler, Surface complexation on $\mathrm{TiO}_{2}$. I. Adsorption of $\mathrm{H}^{+}$and $\mathrm{Cu}^{2+}$ ions onto $\mathrm{TiO}_{2}$ (anatase), J. Colloid Interf. Sci. 169 (1995) 284-290.

[29] J.A. Dean, Lange's Handbook of Chemistry, 13th ed., McGraw-Hill, New York, 1985.

[30] L.A. Davis, D.B. Kent, Surface complexation modeling in aqueous geochemistry, in: M.F. Hochella, A.F. White (Eds.), Reviews in Mineralogy. Mineral-Water Interface Geochemistry, vol. 23, Mineralogical Society of America, Madison, WI, 1990, pp. 177-260.

[31] G.M. Fu, H.E. Allen, Cadmium adsorption by oxic sediment, Water Res. 26 (2) (1992) 225-233. 